\title{
Atención Primaria de Salud en Argentina: proliferación desordenada y modelos en conflicto*
}

Primary Health Care in Argentina: disordered proliferation and conflicting models

Analía Bertolotto', Ana Fuks², Mario Rovere ${ }^{3}$

' Licenciada en Psicología; Miembro de la Asociación Civil El Ágora - Buenos Aires (BA), Argentina.

ana_fuks@yahoo.com

2 Fonoaudióloga; Miembro de la Asociación Civil El Ágora - Buenos Aires (BA), Argentina. analiabertolotto@hotmail.com

${ }^{3}$ Decano de Ciencias de la Salud de la Universidad Nacional de la Matanza (UNLaM); Director de Maestría en Salud Pública del Instituto J. Lazarte de la Universidad Nacional de Rosario (UNR) - Rosario; Coordinador general adjunto de la Asociación Latinoamericana de Medicina Social ALAMES; Director de la Sede Buenos Aires de la Asociación Civil El Ágora - Buenos Aires (BA), Argentina.

mrovere@fibertel.com.ar
RESUMO Una reconstrucción del campo de la salud en Argentina ha permitido verificar que, bajo la denominación genérica de la Atención Primaria de Salud, se han cobijado un conjunto de dispositivos de atención provenientes de diferentes tradiciones de la Salud Pública, entretejidas a su vez por los disímiles modelos políticos que se sucedieron en Argentina antes y después de 1978. El plan de la presente investigación previó una fase de indagación con referentes históricos de la Atención Primaria de Salud y una de trabajo con responsables de los procesos de formación de posgrados que participaron en el proceso de construcción de conocimiento y en la especulación sobre la aplicación de los resultados.

PALAVRAS-CHAVE: Contexto histórico-político; Modelos de Atención Primaria de Salud; Marcas y huellas; Sistema de salud de Argentina.

\begin{abstract}
A historical study of the health field in Argentina allowed to verify that the generic concept of Primary Health Care has recruited a cluster of different models coming from many initiatives of international Public Health experiences. These traditions were pragmatically combined by the political waves that draw a dramatic and a polar sequence from 1978 until nowadays. The research plan included a historical component, using documents and former stakeholders' interview, and a prospective one with work of postgraduate educators that had preliminary results, questions, and challenges in order to explore the future of the Primary Health Care.
\end{abstract}

KEYWORDS: Historical and political context; Primary Health Care models; Traditions and clues; Argentinean health system.

\footnotetext{
* Resultados de un proceso de investigación que forma parte de un estudio multicéntrico sobre la polaridad de la Atención Primaria de Salud Selectiva, Integral o Comprensiva, promovida por el Movimiento por la Salud de los Pueblos con los apoyos técnico y financiero de la Universidad de Ottawa y el Fondo Teasdale-Corti del Gobierno de Canadá.
} 


\section{Introducción}

La Declaración de Alma Ata acontece en una época en que la mayoría de los países de la región de América del Sur estaba gobernado por dictaduras militares. En el caso específico de la Argentina, la Declaración coincide justamente con un momento crucial del desmantelamiento del sistema sanitario nacional y de la transferencia de servicios y responsabilidades a las provincias.

La atención sanitaria de carácter extrahospitalario tenía entonces ya una larga tradición, que provenía de los programas sanitarios que se habían promovido en las zonas rurales del Norte del país asociado a los cultivos industriales (azúcar, algodón y tabaco) (ALVARADO, 1978); y la otra orientada a las periferias de las grandes ciudades, dinamizada a partir de los años 1960 por los programas maternos-infantiles y el ingreso de las técnicas de planificación familiar (ROSEN, 1993).

Durante la dictadura (1976-1983), la atención desconcentrada en las zonas periurbanas fue desalentada y en algunos casos reprimida, básicamente porque el conflicto político-militar de la década tenía como escenario casi excluyente a las grandes ciudades. En cambio, se reinstaló en algunas provincias un programa financieramente asistido de alcance nacional, que se conocía como Salud Rural.

Cuando se produjo la reunión del Alma Ata, esta denominación ya era insuficiente porque los programas territoriales venían extendiéndose a ciudades de pequeño y mediano portes, y se decidió rebautizar a los mismos como programas de Atención Primaria de Salud (APS).

La estrategia queda así asociada a

un conjunto de acciones sanitarias programadas, de baja complejidad y conducidas por médicos, a partir de un hospital base que - como brazo extendido - llegan a la población a través de centros periféricos y los agentes sanitarios, mediante rondas sanitarias [...] (ARGENTINA, 1978, p. 7).

, en la que la activa participación comunitaria fue uno de los componentes más abiertamente deformado.
En una muestra rayana con el cinismo, este documento de la Secretaría de Salud de la época enunciaba por entonces el esfuerzo que debían hacer los servicios y las diferentes organizaciones de la comunidad, mencionando los derechos en salud de la población, mientras reprimiendo ferozmente cualquier actividad considerada política o subversiva.

A partir de la transición democrática en los años 1980 , se abrieron nuevas y mejores condiciones para aquellos componentes de la estrategia que podrían ser considerados más políticos. Sin embargo, la re-politización del espacio comunitario fue pensada básicamente desde un área de política social (programas alimentarios), que fundó un progresivo aislamiento entre la política social en sentido restricto y el sector salud, a lo que deben sumarse las marcas que dejó una dictadura con 30.000 desaparecidos, prolongando los efectos de la represión en forma de autocensura por muchos años más (BERMANN et al., 1994).

Así, una tímida expansión del primer nivel y una igualmente tímida apertura de espacios de aprendizaje para la formación de los equipos de salud se quedaron limitadas a una extensión de cobertura tecnocrática, que creó las bases para una posterior medicalización de la APS.

Años más tarde, y luego de una severa crisis económica que indujo una alta concentración de poder aun en el marco democrático, se inicia en los 1990 un período caracterizado por la adopción de políticas neoliberales, con el consecuente vaciamiento del Estado y la aparición del mercado como la principal voz autorizada para dictar la agenda pública. Respecto de las políticas sanitarias, se consolidó una fuerte tendencia hacia la mercantilización de la salud.

En este contexto, la estrategia de APS se vio traducida al acceso de un paquete mínimo de intervenciones focalizadas, ocultando y aislando a la salud de cualquier reflexión sobre los determinantes sociales, económicos, culturales y urbanísticos, y, lógicamente, incapaz de dar respuesta al desafío que implicaba generar un nuevo modelo de atención intercultural para abordar la cuestión migratoria, que, por entonces, se incrementaba (BANCO MUNDIAL, 1993).

Resulta curioso que cuando se consulta a los entrevistados más jóvenes sobre las 'marcas que dejaron 
la Dictadura', ellos contestan refiriéndose a esta década (los 1990), como si a pesar del cumplimiento de las formalidades democráticas, la orientación económica neoliberal, el clima institucional autoritario, la flexibilización laboral y el retroceso en derechos humanos hiciera que los jóvenes percibieran más las similitudes y asociaciones entre democracia neoliberal y Dictadura Militar que sus diferencias ${ }^{1}$. No se trata sólo de coincidencias simbólicas. En muchas jurisdicciones, se reciclaron funcionarios civiles de la Dictadura y políticas muy afines con ese período, como el caso de la erradicación forzosa de villas de emergencia, incrementando la sensación de un período de restauración autoritaria.

En el esquema siguiente se expone una línea de tiempo que sintetiza los procesos técnico-sanitarios y políticos que caracterizan el período que el estudio pretendió cubrir. Se llama así la atención sobre el papel de las crisis cíclicas que fueron forjando la historia política, pero también social y económica, de la democracia en la Argentina (Figura 1).
Como consecuencia de la crisis del 2001-2002, la Argentina se vio frente a un desafío muy similar al que enfrentan hoy las naciones del Sur de Europa, optando en la encrucijada por retomar el control monetario y un conjunto de políticas que influyeron y se vieron influidas por uno grupo creciente de países de la región que buscaron alejarse del Consenso de Washington, un instrumento de política internacional paradigmático de los 1990. Se inició así un nuevo período caracterizado por cambios 'acompasados' en la región latinoamericana y particularmente del cono Sur, con gobiernos progresistas que apuestan a la importancia geopolítica de la región, a la cierta redistribución del ingreso y, fundamentalmente, al resurgimiento de Estados presentes y actuantes (ABAL MEDINA, 2006).

De diferentes maneras, un conjunto de medidas económicas y sociales que permiten mostrar resultados favorables sobre 'los determinantes' expresados, en el caso de Argentina, en mejoras de las tasas de actividad económica, empleo, calidad del empleo, políticas

Figura 1. Crises Argentinas

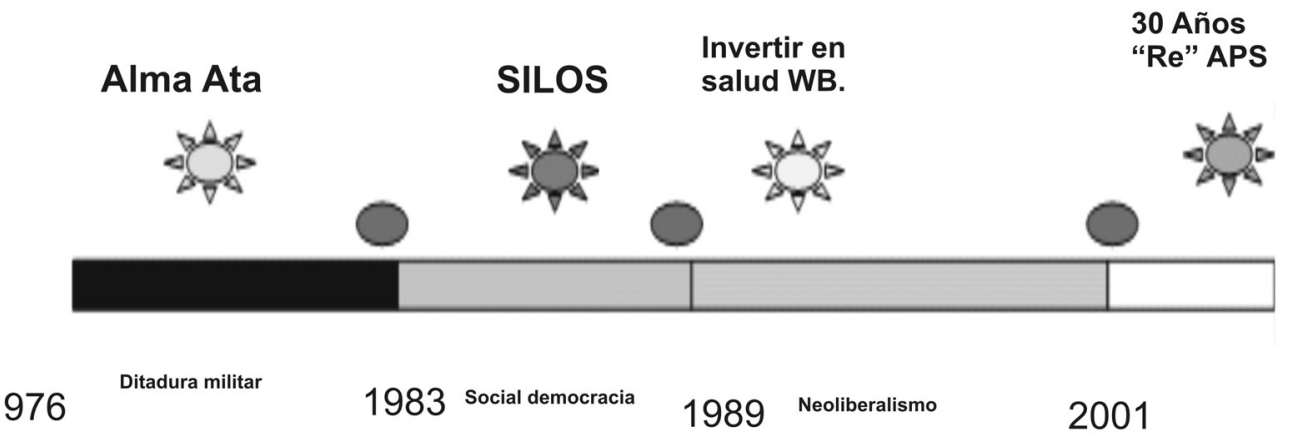

Fuente: Elaboración propia.

antidiscriminatorias para inmigrantes y subsidios de carácter progresivo y compensador; sin que esto logre, no obstante, reflejarse aún en políticas de salud transformadoras que apunten, en la práctica, a resultados de mayor equidad en el acceso y en la calidad de los servicios; un componente ineludible en la construcción del derecho a la salud.
A pesar de las contradicciones del período, o quizás por ellas, se verificó una expansión significativa del personal de salud que se desempeńa en el primer nivel de atención (ARGENTINA, 2007).

La descentralización política permitió que múltiples instancias provinciales, y sobre todo municipales, 'se animaran' a abrir centros de salud, los cuales, en

\footnotetext{
Tomado del registro de un focus group realizado en agosto de 2010 donde se exponen los resultados del primer tramo de la investigación ligado a las marcas y huellas que la dictadura deja en las practicas de los equipos de salud del primer nivel.

${ }^{2}$ Tomado de entrevista a informante clave.
} 
ausencia de una política rectora, impulsaron un verdadero 'collage' de modelos de impacto cruzado, en la medida en que una proporción creciente de los presupuestos de las residencias médico-profesionales y otros programas de formación de posgrado fueron dedicadas a especialidades que utilizan el primer nivel como escenario de aprendizaje ${ }^{3}$.

Cuantificar este crecimiento no es tarea sencilla, ya que se carece de una línea de base, y puesto que se trata de un país con un sector salud altamente fragmentado. Un censo reciente del Ministerio de Salud de la Nación estima que poco menos de 70.000 trabajadores de salud en sus diferentes categorías (cerca de un $12 \%$ de la fuerza laboral del sector) se desempeñan en el primer nivel del subsector público. Muchos de ellos con formas de contratación precaria o engañosa (becas, contratos a término).

El balance de 30 años de las políticas marcadamente diferentes muestra, sin embargo, un rasgo común: el estancamiento y aun el retroceso del desarrollo de la infraestructura pública en salud generando, como consecuencia de la desproporción de un primer nivel que se expande en la precariedad y en la informalidad; y una inversión en el segundo y tercer nivel que retrocede, un fenómeno que se caricaturiza en la expresión "en muchos casos, el primer nivel de atención devino en un primer nivel de contención" (EL ÁGORA, 2009).

En síntesis, reviendo los más de 30 años que van desde la Declaración de Alma Ata al presente, se constató que la aplicación de las distintas perspectivas e interpretaciones de APS en nuestro país tuvieron un claro correlato con los distintos períodos políticos que atravesó la Argentina en esos años. Establecer el peso que los avances, los retrocesos, las resistencias y las omisiones mantiene sobre las posibilidades y potencialidades de transformación, fue el problema que motivó esta investigación, especialmente considerando que una parte significativa del personal que se desempeña en el primer nivel se encuentra vinculado a procesos de formación, y por ende, pueden ser protagonistas para revertir las determinaciones que mantienen amarrado al sector salud en la medida en que las mismas se hagan más conscientes y objetivables.

\section{Metodología}

\section{Puntos de partida}

A partir del relevamiento de datos realizado, se cotejó que la proliferación de centros de salud en los últimos 30 años, fundamentalmente en la zonas urbanas y periurbanas, sin una necesaria vinculación con aquello de las necesidades de poblaciones que crecen y se pauperizan con la pérdida del empleo estable, y la creciente inmigración de población de países limítrofes, acompaña una expansión de trabajadores en el primer nivel de atención, lo cual alcanza un gran porcentaje de la fuerza del sector, hibridizada con agentes sanitarios o promotores de salud que se han sostenido por más de tres décadas bajo formas precarias de relaciones laborales; determinando una composición y distribución de centros muy diversa, la mayoría de los cuales define por su cuenta las funciones y los desempeños esperados en el primer nivel de atención y el grado de articulación con el resto del sistema de salud.

Sobre el supuesto de que las marcas históricas se revelan como huellas y rastros en las concepciones y prácticas de los trabajadores y formadores en APS y la constatación de que la prestación de Salud Pública se mantiene 'congelada' en un conjunto de actividades que proliferan sin coordinación ni planificación estratégica, desde un paradigma histórico eminentemente médico y medicalizado, sin articulación interdisciplinaria ni intersectorial y sin adecuación tecnológica ni intercultural; desplegamos las referencias, testimonios y evidencias hallados en esta investigación.

Apoyados en las herramientas analíticas de autores como Bourdieu (2006) para comprender los mecanismos que legitiman invisiblemente los hábitus - esquemas o disposiciones de percepción, apreciación y acción interiorizados - que tienden a aceptar el orden establecido y construyen las 'falsas evidencias' de la formación hegemónica; en los conceptos de Verón (1987), Freud (1986) y Derrida (1998) que nos han servido para comprender cómo desde las huellas discursivas, a través de los nomos y las costumbres que se naturalizan, pueden operar como marcas didácticas los hechos del pasado,

\footnotetext{
${ }^{3}$ Tomado del registro a informantes clave a saber: referentes de formación de postgrado, residencias; Programa Nacional de Médicos Comunitarios; y programa de profesionalización de promotores sanitarios. Información recogida en el segundo tramo de la investigación.
} 
siendo susceptibles de sucesivas re-interpretaciones; y en Foucault (1992) que nos muestra también cómo el enfrentamiento de los saberes singulares o insuficientemente elaborados, con aquellos validados popularmente y asimilados como 'científicamente serios' componen un acoplamiento de conocimientos que, en su conjunto, conforman la 'genealogía' de la memoria colectiva; completándolo a su vez con Ricoeur (2004), en la idea de la 'tradición' que fluye subterráneamente y desvelaque la distancia temporal que nos separa del pasado no es un intervalo muerto, sino una transmisión generadora de sentido. Recorrimos y aprovechamos las afluentes históricas de la APS para comprender los ejes sobre los cuales se ha constituido la polaridad integral/selectiva que fue analizada, lo que permitió avizorar las distintas corrientes o tradiciones que, como 'retornos del saber', la han surcado históricamente para moldearla en las producciones que describimos.

Dichos retońos surgen de documentos, escritos o entrevistas y apuntan a visibilizar las 'marcas' que han operado y operan en la interfase salud/población como un modo de recuperar, tanto para el análisis como para la intervención, el complejo entramado de factores que han bloqueado la implementación genuina de la estrategia en los últimos 30 años. Esto es un punto de partida para posibilitar que el colectivo salud revise su rol a lo largo de esos años, y se asuma como actor político de peso frente a los tomadores de decisiones 'tradicionales' (Figura 2).
El estudio, más precisamente genealógico que histórico, se centró, en una primera etapa, en los aprendizajes y en las deficiencias observadas en el desarrollo de la estrategia de APS en la Argentina, a partir del análisis de testimonios que suscitaron un estudio comparativo de dos territorios considerados emblemáticos y muy diferentes entre $s^{1}$.

La Villa 31, cercana al puerto e instalada en el corazón de uno de los barrios más cotizados de la ciudad de Buenos Aires y por ende, casi la única imposible de invisibilizar; poblada al ritmo de los procesos migratorios de la ciudad para cubrir las necesidades vicariantes de su mercado de trabajo - a principios del siglo 20, con españoles, italianos y polacos; hoy con pobladores de origen boliviano, paraguayo y migrantes de varias provincias del norte argentino - ha sido objeto de 'períodos de tolerancia', alternados con varios intentos de erradicación, logrando resistir incluso a los gobiernos militares. Esta zona favelada, también llamada "Villa Miseria”, es un 'asentamiento irregular' sobre terrenos fiscales, cubierta con centros de salud que se expandían o reducían, o incluso se erradicaban, al ritmo de las políticas urbanísticas de cada período (BLAUSTEIN, 2001).

El Departamento de General Güemes, que es un conjunto de tres municipios urbano-rurales del Noroeste argentino en la provincia de Salta, a escasos 200 $\mathrm{km}$ de la frontera con Bolivia, cuya economía local se basa fundamentalmente en la explotación industrial

Figura 2. Desarrollo de la investigación

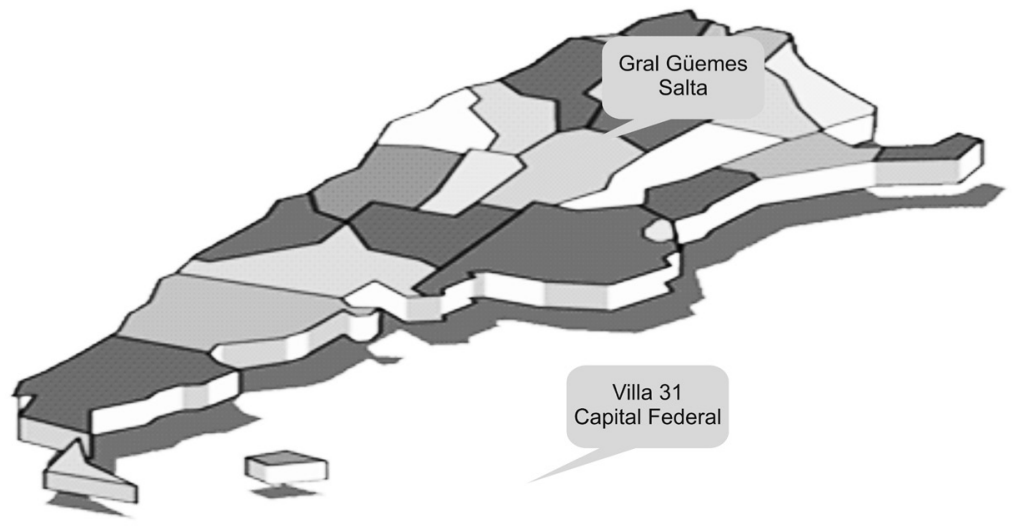

Fuente: Elaboración propia.

${ }^{4}$ Material producido a partir de un instrumento de análisis de elaboración propia. Cantidad de entrevistas en la primera etapa: 16. 
de cultivos como el azúcar, el tabaco y la producción de cítricos, ha vivido las idas y vueltas de la política argentina constituyendo uno de los primeros ámbitos de resistencia a las políticas neoliberales que generaron desocupación masiva ${ }^{5}$. Además de una experiencia sanitaria paradigmática en este territorio, funciona la escuela provincial de formación de agentes sanitarios, o sea, el recurso humano por antonomasia de los programas de Salud Rural y APS (SIERRA E IGLESIAS, 1993).

Sobre la base de este estudio de casos, la investigación se amplió hasta abocarse a los interrogantes sobre hasta qué punto el sector salud percibe y puede superar mandatos, algunos de los cuales operan como verdaderas marcas; y más aún qué intensidad podrían asumir las intervenciones educativas en términos de aprendizajes significativos pero también de desaprendizajes, para revertir, en la formación de las nuevas generaciones, los temores o las limitaciones que impiden que la propia APS pueda devenir en una herramienta de desarrollo de las comunidades ${ }^{6}$.

En este sentido, los principales interrogantes de la presente investigación fueron: ¿A qué se deben la heterogeneidad de modelos de APS desplegados en los últimos 30 ańos en Argentina?; ¿Cómo el sector salud se ha articulado con los diferentes dispositivos de represión y disciplinamiento desde la Dictadura y de las políticas neoliberales?; ¿ Hasta qué punto se han percibido y elaborado estas marcas en el colectivo salud? y ¿De qué forma se pueden revertir sus huellas en la formación de las nuevas generaciones?.

La investigación se desarrolló aplicando una combinación heurística de herramientas de investigación comparando técnicas objetivantes (relevamiento documental y bibliográfico) y relevamientos intersubjetivos (entrevistas estructuradas, semiestructuradas y en profundidad, realizadas a trabajadores, profesionales, agentes sanitarios y funcionarios de instancias del gobierno nacional, provincial y municipales); observación participante en los escenarios seleccionados y grupos focales; a efectos de detectar y aprovechar incongruencias, va- cíos de información y previniendo sesgos que pudiera aportar el acercamiento desde una única perspectiva.

Un instrumento de análisis de elaboración propia permitió identificar en los discursos los componentes de la APS a través de un esquema de exploración heterodoxo y cualitativo, que puede enmarcarse en la técnica de análisis de discurso o de contenido, en el que fueron diferenciados cuatro planos:

- textos son enunciados literales que documentados y analizados forman parte del aparato erudito de la investigación;

- contextos son el análisis de un conjunto de elementos históricos que rodean, interpenetran y ayudan a explicar y comprender las diferentes dimensiones del objeto de estudio;

- subtextos son un análisis de rastros, huellas y marcas que subyacen reprimidos, pero que emergen de una forma u otra en el campo discursivo de los textos; e

- intertextos que son las referencias cruzadas y apoyaturas en otros textos, documentos, autores y autoridades.

\section{Resultados}

En las entrevistas a los informantes-clave, se pudo constatar cómo los escenarios seleccionados son y fueron en sí mismos protagonistas y espejos de las dimensiones de análisis estudiadas y de lo sucedido en este período, para establecer en qué medida la impronta de 'esterilización' de los componentes más sociales y políticos de la APS restringió la acción a un paquete mínimo de intervenciones altamente focalizadas, debilitando las propuestas transversales y más articuladas a los servicios de salud.

Como ejemplo, dos agentes sanitarios que vivieron en Gral. Güemes en el periodo de la Dictadura Militar manifestaban:

${ }^{5}$ Referencia de informante clave respecto al origen de las manifestaciones de resistencia popular en los años 1990, denominadas Piquetes (cortes de ruta como medio de protesta) en oposición a las políticas neoliberales de esa década.

${ }^{6}$ Incluye al segundo tramo de la investigación en que se entrevistan a 16 referentes de experiencias innovadoras de formación profesional: siete de Ciudad de Buenos Aires, cinco del Ministerio de Salud de la nación y cuatro de la Provincia de Buenos Aires; y se realizan dos focus group protagonizados por esos mismos referentes. 
[...] en el 1978, nace APS...con la condición: sin participación comunitaria. Asi de clarito. Todo lo que nosotros queramos, pero sin la participación. Digamos, por favor, [se decía en ese entonces] no patrocinen la subversión [...].

De forma similar, amplían:

[...] en los 1990, empieza a desaparecer todo [se refieren a lo que habia empezado a recuperarse a partir de la transición democrática]: los ferrocarriles, la gente, y se empieza a apagar todo el sistema [...] y empiezan a aparecer situaciones muy puntuales [...] la estrategia de la APS se empieza a dirigir de distintas maneras. De muy diversas maneras. Fijate vos que pierde la esencia fundamental, que es la democratización de la participación, la pierde. Porque ahora te la imponen, de qué manera?[...] Cuando estábamos en la Punilla (una localidad de Salta), en la comunidad, ibamos a trabajar con plena participación de todos, cuando participa la gente. Vos haces con ellos, ahi esta. Fijate, para nosotros, eso es la Atención Primaria. Vos no te imagináis en lo que nos transformamos los agentes sanitarios. Tienes que estar muy bien parado para luchar, para sobrevivir en esto de la estrategia de APS.

Surge aquí un subtexto 'peligroso': los agentes sanitarios viven las tensiones y usos de la política que divide a quienes se pudieron profesionalizar porque provienen de las épocas 'tecnocráticas de la Dictadura' que hicieron los cursos de formación y los 'simples punteros', como se denomina a quienes ingresaron sin formación, visualizados como cuadros de partidos políticos que lideran actividades que son consideradas de 'uso político' por parte de los agentes más 'profesionalizados'.

En la Villa 31, un trabajador social expresaba, refiriéndose a la misma época, que: "[...] lo único claro que había a principios de los 1990 era que no querían que se trabajara abiertamente con los representantes de la comunidades [...]”. Así lo estipulaba, según sus dichos, el jefe del área:

\section{[...] Habia una indicación clara de no acordar} con referentes politicos, de no salir. Esto generaba cuestiones internas dentro del equipo porque habia gente que salia igual y acordaba igual con algunos referentes de la villa.

Algunos profesionales, con resonancias de ideologías y prácticas de los 1970, realizaban sus tareas al margen de las consignas dominantes, pero voluntariamente y en aislamiento.

Así, en la entrevista con otros dos agentes sanitarios de Gral. Güemes, se habla del contraste de prácticas entre el comienzo del programa y la actualidad, con la experiencia acumulada:

[...] de alguna manera, era muy diferente a lo que es hoy, en un periodo totalmente democrático y en aquella época, el proceso [militar]. No permitían ciertas cosas. Si se quiere, la estrategia, de alguna manera, estaba basada en tres puntos: cobertura, participación social - ése era un inconveniente - y las relaciones intersectoriales. Entonces, con lo que era la cobertura no hubo problema, si hubo problema con la participación social, porque no se podian hacer reuniones, no se podian hacer convocatorias, y era una dificultad. Además de la visita domiciliaria, digamos que es la tarea fundamental del agente sanitario, desarrollamos programas como inmunizaciones, que son nacionales, programas de tuberculosis, programas de materno-infantil, son todos programas de APS que desarrollamos dentro de lo que es la tarea semi-institucional del agente sanitario, porque en realidad, el agente ha nacido para ser y pertenecer a la comunidad y desde ahi, un poco de la institución.

Otros testimonios hablan de una mayor e incipiente conciencia de cambios en los últimos tiempos: "[...] ahora por lo menos se empieza a entender, desde lo semántico, que (APS) es un poco más allá de las acciones focalizadas, que es una estrategia”. 
Se verifica en ambos escenarios que a pesar de tratarse de espacios de fuerte movilización política, la participación social, la interdisciplina, la intersectorialidad y la interculturalidad no han logrado instalarse en las prácticas cotidianas de los equipos y de la comunidad. Es más, la ausencia de estos elementos ni siquiera se percibe como fragilidade en sus habitus o en los modelos de atención ${ }^{7}$.

\section{Conflicto de modelos y proliferación desordenada}

En los escenarios analizados, las prácticas y los discursos de los trabajadores responden predominantemente a dos modelos polares. En Gral Güemes se condensa la historia de un enfoque heredero de la lucha contra las enfermedades vectoriales generalmente agrupadas con el nombre de las enfermedades tropicales. A principios de los 1960, los éxitos logrados estimularon a ensayar modelos programáticos más transversales que se conocieron en Venezuela como 'Medicina Simplificada'; y en Argentina debutan en la provincia de Jujuy en 1967 por iniciativa del doctor Carlos Alvarado, quien había sido director del programa de erradicación de la malaria de la Organización Mundial de Salud (OMS). Su accionar se cumple a través del reclutamiento y entrenamiento de agentes sanitarios o trabajadores comunitarios que acuden casa por casa (rondas sanitarias) para realizar acciones de inmunizaciones, control de crecimiento y desarrollo de niños, detectando y controlando la malaria, la tuberculosis, el paludismo, la hanseniasis y otras enfermedades endémicas, mejorando el saneamiento rural y promoviendo huertas familiares, entre otras acciones.

En la Villa 31 se han ensayado modelos de atención que hunden sus raíces en el origen mismo de la higiene urbana que nace estrechamente asociada al servicio religioso y del cual tarda bastante en separarse (ROVERE; SACCHETTI, 2001). Identificada histórica y fundamentalmente a la tarea femenina, y cuando aún el cuidado de la salud no estaba subordinado al saber científico ni asociado a la curación física del cuerpo, se distingue más como una tarea social destinada al auxilio de niños, ancianos, pobres, y discapacitados. La misión, en estos casos, no es sólo la curación o la atención de la salud, sino la educación con conocimientos y valores de circulación normal, entre las capas medias de la sociedad.

Un entrevistado, ex-Ministro de Salud de Salta, pionero colaborador del doctor Alberto Alvarado en la Provincia vecina de Jujuy mencionó:

[...] Para el año 1976 ya teníamos toda la provincia cubierta con el programa de Alvarado. Después, en el 1976, me tuve que ir exiliado a Centroamérica, porque las personas que haciamos estas cosas raras éramos subversivos, entre comillas. Estuve trabajando en Honduras, en Nicaragua, cuando en el año 1978 no podía aguantar no vivir en mi patria, me volví. Pude ingresar, pude empezar a trabajar en Salta y en Salta empezamos a desarrollar el plan de Jujuy $y$ era la misma historia, porque teniamos departamentos en Salta en los años 1978 y 1979, que nos encontrábamos con 80 o 90 por mil de Mortalidad Infantil. Y ahi empezamos a vacunar casa por casa, nutrición, medio ambiente, bueno, toda una historia larga [...].

En contraste, en la Villa 31, surcada hasta el golpe castrense por una militancia sanitaria cercana a algunos movimientos cristianos, se generó una intensa represión ya que su origen y vinculación misional afín a los preceptos de la 'opción por los pobres' de la iglesia del tercer mundo fue duramente perseguida. Una trabajadora social de aquella época nos cuenta:

[...] en el 1973, sabiamos quienes eran los delegados del barrio y habia una comunicación. Cuando nosotros empezamos estaba el padre Mugica ${ }^{8}$ en la villa. Habia un delegado que

${ }^{7}$ En nuestras culturas predominan ideologías conservadoras que sirven a los intereses particulares de la clase dominante, 'sistemas simbólicos' que, en cuanto instrumentos estructurados y estructurantes de comunicación y de conocimiento, cumplen su función política de imposición o de legitimación de un orden, y ayudan a asegurar el predominio de una clase sobre otra (violencia simbólica y de la otra) (Bourdieu, 2006).

${ }^{8}$ Miembro del Movimiento de Sacerdotes para el Tercer Mundo (MSTM). Movimiento que buscaba construir una Iglesia comprometida con los más pobres y con las luchas populares de liberación que se dieron en las décadas de 1960 y 1970. Asesinado el 11 de mayo de 1974. 
sabía todo, y nosotros teniamos forma de comunicarnos y de hacer cosas. En el 1976, se cae todo. Fue terrible!

Y con mucha angustia y temor aún, nos relató:

[...] Cacciatore ${ }^{9}$ les pasó la topadora por encima!' A partir de alli, quedó un grupo trabajando - en el Programa Materno-Infantil - exclusivamente en el consultorio de Pediatría, pero no en el Centro, sino en el Hospital, desde donde se repartía leche, hasta los 1980, en que se crean las Áreas Programáticas [áreas geográficas que dependen de los hospitales para su cobertura sanitaria] y se vuelven a activar los Centros del barrio y de la Villa.

En este caso, y a diferencia de lo ocurrido en los sectores rurales o semi-rurales, se combinaron la 'lucha contra la subversión', el racismo enquistado en las capas superiores de las clases dominantes y los intereses que las inversiones inmobiliarias de lujo mantienen aún hoy en permanente lobby para ocupar el valioso territorio de este asentamiento ubicado en una micro región entre las que se encuentra la principal terminal de ómnibus y la principal terminal de ferrocarriles del país.

Una diferencia sustancial se da entre las participaciones social y política y la dispensarización o trabajo casa por casa como manera de organizar la APS. Nuevamente una entrevista ayuda a entenderlo:

...cuando Alvarado regresa [mediados de los 1960], encuentra un marcado retroceso en lo que habia sido la lucha contra las enfermedades endémicas. Jujuy en ese tiempo tenía 134 por mil de mortalidad infantil!' A él realmente le dolia lo que veía, porque había paludismo de vuelta, la tuberculosis era terrible, todas las enfermedades que caracterizan a una zona donde no hay atención de la salud, donde no hay medicina sanitaria, donde no hay prevención de la enfermedad. Ahi diseña un programa de salud para Jujuy y nos empezó a explicar qué era lo que quería hacer. Nosotros, por supuesto no podíamos creer lo que estábamos escuchando! Nosotros habiamos sido formados en una facultad de medicina tradicional de la Argentina. $Y$ este señor nos propuso que para preservar la vida y la salud de la gente habia que ir casa por casa, la consigna era cobertura total ${ }^{10}$.

Mientras que en la Villa 31 se destaca en los trabajos intersectorial o interdisciplinario por su énfasis en lo educativo-asistencial. En palabras de un referente que trabajó en esa Villa y luego tuvo distintos cargos sanitarios en la ciudad de Buenos Aires:

En el 1968, 1969, en el grupo que se llamaba de Salud Materno Infantil, habia un Programa de Educación para la Salud, compuesto principalmente por rondas sanitarias, al estilo de Alvarado. En lugar de tener personal de la propia comunidad que hacía la ronda sanitaria, no sé si Alvarado les pagaba o lo hacian en horarios que no eran las de su trabajo, nosotros teniamos para esto asistentes sociales a disposición. Ellas eran las que tenían que salir. La Villa se podia recorrer en esa época. El Programa de Educación para la Salud significaba que cada familia recibia cada dos o tres meses una visita de la asistente social, quien controlaba los aspectos médicos, vacunas, leche, y también se daban algunas consignas de Educación para la Salud. Entonces, todo el centro y toda la población colaboraban.

A partir de la recuperación de la democracia, en ambos escenarios, aunque se percibe cierta tensión de las experiencias con el segundo nivel de atención (los hospitales), es notable cómo el modelo médico avanza casi imperceptiblemente en este terreno conquistando sus prácticas, en las palabras de un trabajador social:

\footnotetext{
${ }^{9}$ Intendente de la ciudad de Buenos Aires durante la dictadura de 1976.

${ }^{10}$ Extraído de una entrevista al doctor Enrique Tanoni que, en 1978, fue el primer jefe del programa de Salud Rural en Salta y posteriormente, a partir de 1983, Ministro de Salud de esa Provincia.
} 
Yo creo que el Centro tiene una dinámica más de consultorios externos. La mayoría de los profesionales son profesionales formados para hospitales, clinicas, no son formados para APS, incluso los formados para APS como yo entran en la dinámica de consultorio, y me incluyo. Trabajar con la comunidad, con la gente siempre es más bardo, es más difícil, es más fácil quedarme en el consultorio que salir a recorrer casa por casa, que armar actividades afuera, que lidiar con la gente de los comedores o con los referentes barriales. En el Hospital F., lo social es visto como algo que no tiene que ver con la función de los servicios, es algo rudimentario, complementario, no de tanta valía, en el ámbito de la salud, en general, lo social ocupa lugares secundarios. afirmó:

Otro entrevistado, referente de capacitación

[...] Convengamos que el primer nivel, en muchos lugares, se está manejando como una guerra hospitalaria, .esta desarticulación que tiene la politica sanitaria repercute en estas acciones, en las prácticas.

A pesar de que la participación social como derecho y como responsabilidad es registrada como uno de los componentes esenciales de la estrategia de APS, en ninguno de los espacios analizados se desarrolla plenamente esta dimensión, presentando dificultades para ser reconocida y pensada por los actores en sus prácticas. La misma es habitualmente subentendida como un modo de 'colaboración' o de 'contención' de la población a la que se le ofrecen los servicios. Al respecto, una licenciada en nutrición y docente de agentes sanitarios del programa de Salud Rural de Salta relató:

[...] yo creo que costó mucho la participación de la comunidad en la resolución porque no estábamos informados ni preparados para tener participación comunitaria, porque no nos olvidemos que veníamos de años de un proceso donde la dictadura era muy verticalista y no habia participación alguna y hablar de comunidad era una mala palabra, entonces creo que romper ese eslabón dentro de la sociedad costó mucho en las tomas de decisiones.

Quizás más paradojal resulte si se considera que los dos escenarios seleccionados resultan ejemplos paradigmáticos de lucha política, de resistencia activa de la ciudadanía contra políticas de exclusión, de desempleo, pero que los movimientos sociales que allí se han expresado a grandes rasgos no han incluido reivindicaciones de salud en su agenda.

En la etapa de exploración con los referentes capacitadores, la dificultad para pensar en el rol de la participación comunitaria en el diseño de los currículos de formación de los nuevos recursos humanos fue patente, a tal punto que su ausencia ni siquiera se percibe como una fragilidad de sus modelos de atención.

Una alta referente de capacitación a nivel nacional nos dijo:

[...] Uno habla con la gente y las críticas no apuntan a cambiar la formación del médico ó del psicólogo ó el trabajador social. Que cambiaría el horario de atención, la forma de conseguir el turno, cosas que tienen que ver con lo cotidiano, me gustaría cambiar un montón de cosas en la currícula pero no se me ocurre, cómo [incluir a la] población, qué injerencia puedo tener. No sé cómo. Sin ser parte de una comisión de graduados, sin ser parte de una asociación profesional. Me parecería maravilloso que se pueda pero no sé cómo [...].

Uno de los referentes de capacitación en APS comenta en sentido propositivo:

[...] nosotros tenemos que refundar cada vez la APS, y todavia, en nuestros discursos, se refundan los $1990 \ldots$ se ve con pequeñas cosas. Hoy se habla mucho de evidencia, de eficacia, de eficiencia, de recursos humanos, y son terminologías que se usaron mucho en los 1990. Estamos en una pelea, te diría que, ideológica [...]. 
Con más énfasis aún "[...] en cuanto a impacto yo diría que no hay, no hay logros. No ha habido impacto de ninguna de esas políticas" (refiriéndose a la formación en APS integral). Otra referente de capacitación define a los espacios de aprendizaje en el 1er nivel de atención diciendo que

[...] no son espacios previamente pensados... Hay buenas intenciones, pero no se sabe cómo. Los profesionales sin experiencias previas les tienen miedo a las personas. Hacen cosas de buena onda con la gente, pero asi no se sostienen. ¿Qué participación comunitaria podemos construir? Hay una permanente tensión entre asistencia y prevención.

\section{Conclusiones}

Parece verificarse que, si bien no eran perceptibles para los propios actores, las concepciones y las prácticas se encuentran signadas por la frontera invisible de las 'marcas indelebles de la dictadura', y por ende la ausencia de un enfoque participativo-social que incorpore una acción intersectorial y una perspectiva intercultural, se presenta como funcional a estos impalpables límites.

Las formas amputadas de toda dimensión política, que alentara la mínima promoción de participación comunitaria o social, ahondaron, a su vez, las huellas por las que las sucesivas generaciones de profesionales recorrieron y se reprodujeron hasta la actualidad. Sólo se exceptuaron a los embates del terrorismo estatal, que actuó fundamentalmente en las zonas urbanas y periurbanas de nuestro país; y a su continuidad 'por otros medios', aunque bastante similares, en las políticas neoliberales de los 1990. Estas son escasas experiencias aisladas que pudieron sobrevivir y recuperar los rastros en los que pudimos perseguir algunos de los principios intencionalmente olvidados y ocultados de la APS.

El estudio se constituyó así como un analizador de las contradicciones políticas e ideológicas que signaron el citado campo durante el período de la Dictadura, la socialdemocracia y el neoliberalismo, al contribuir a visibilizar las huellas, los obstáculos e intereses instalados en la cultura de la población y el propio sector salud, cuyo origen, intensidad y profundidad permanecen ocultos para la observación cotidiana y cuya deconstrucción permite interpelar el rol de los equipos sanitarios como actores políticos que reproducen acríticamente un modelo asistencialista, individual y curativo de atención, o pugnan por su transformación.

Si bien continúa existiendo una multiplicidad de obstáculos que inciden para la efectivización plena de una APS que promueva y acompañe el desarrollo local y la participación social: los intereses de la corporación médica; la industria farmacéutica y de las tecnologías de diagnóstico, la falta de planificación en base a las características poblacionales, la cristalización de modelos formativos que no fornezcan respuesta a las principales problemáticas de salud de los conjuntos sociales, así como los prejuicios de los propios profesionales; aquellas marcas fueron y son su dificultad fundamental.

\section{Algunas recomendaciones a partir de esta exploración}

Retomando los objetivos y el desarrollo de nuestra investigación y confirmando que, si a mitad de la década de los 1970, el primer nivel de atención era objeto de 'experimentación' - con centenas de trabajadores y profesionales con predominio de agentes sanitarios o promotores - algo más de 30 años después de Alma Ata, Argentina cuenta con casi 70.000 trabajadores de salud en el primer nivel (un 12\% del total de la fuerza laboral del sector), con neto predominio de profesionales universitarios, trabajando con las más diversas y flexibles formas de contratación, muchas veces sin responsabilidad territorial, repitiendo el modelo hospitalario de consultorio, y extendiendo las fronteras de acceso a los medicamentos, fuente de un renovado interés en el campo; lo que implica que Argentina es uno de los países que más ha medicalizado y medicamentalizado la APS del mundo.

Ahora bien, el acúmulo histórico que se cobija en el país bajo el nombre de APS contiene suficientes 
herramientas transformadoras como para retomar un sentido de equidad, ya que la presencia de una significativa proporción de fuerza laboral en salud trabajando en el primer nivel comprometida con el derecho a la salud podría al mismo tiempo:

- contribuir significativamente a través de un trabajo intersectorial al desarrollo local en las comunidades en donde se inserta;

- lograr instalar salud en la agenda de comunidades organizadas, movilizadas y protagonistas de su propio desarrollo;

- partir de las cosmovisiones y experiencias propias de las comunidades sobre el proceso salud, enfermedad y atención;

- incidir sobre los modelos prestadores de todos los niveles haciendo del referencial de las redes una oportunidad para adecuar los servicios a las necesidades y a las culturas de los pueblos que allí se atienden; y
- hacer que los escenarios comunitarios e institucionales del primer nivel devengan en espacios fundamentales para repensar la formación de la fuerza laboral en salud con la participación de la población en los diseños curriculares de grado y de posgrado.

No se trata de buenos deseos, sino de una posibilidad cierta a condición de hacer consciente y de remover los mecanismos que reproducen prácticas sociales y profesionales estereotipadas y tecnocráticas.

\section{Agradecimientos}

Colaboraron en esta investigación la Andrea Jait; Eugenia Bagnasco; Martina Iparraguirre; Martín Latorraca y Ingrid Barman; con el apoyo en infraestructura y secretariado de María Pía Ferreira; Candela Burgos y Beatriz Reina (Salta).

\section{Referências}

ABAL MEDINA, J.M. Crisis y recomposición del Estado. Revista Argentina de Sociología, v. 4, n. 7, Buenos Aires, jul./dic. 2006, p. 140-150. Disponible en: <http://redalyc.uaemex.mx/src/inicio/ ArtPdfRed.jsp?iCve=26940707> . Acceso en: 02 mai. 2012.

ALVARADO, C. Pautas para la Cobertura de las Poblaciones Rurales en Sonis: Medicina Sanitaria. Buenos Aires: El Ateneo, 1978.

ARGENTINA. MINISTERIO DE BIENESTAR SOCIAL DE LA NACIÓN, SECRETARÍA DE SALUD PÚBLICA. La Atención Primaria de la Salud en la República Argentina. Buenos Aires: Ministerio de Bienestar Social de la Nación, 1978.

MINISTERIO DE SALUD DE LA NACIÓN. Remediar, Caracterización de los centros de salud del país. Buenos Aires: Ministerio de Salud de la Nación, 2007.

BANCO MUNDIAL. Informe Invertir en Salud. Washington: Banco Mundial, 1993.

BLAUSTEIN, E. Prohibido vivir aquí. Comisión Municipal de la Vivienda del Gobierno de la Buenos Aires, Buenos Aires, 2001.
Disponible en: <www.arteuna.com/RRF/Muro_Blaustein.htm>. Acceso en: 02 mai. 2012

BERMANN et al. Efecto Psicosociales de la Represión Política. Sus secuelas en Alemania, en Argentina y Uruguay. Córdoba: GoetheInstitut, 1994.

BOURDIEU, P. Intelectuales, política y poder. Buenos Aires: Eudeba, 2006.

DERRIDA, J. De la gramatología. México: Siglo XXI, 1998.

EL ÁGORA. Instituto de la Salud J. Lazarte. El campo de la salud en la Argentina: análisis de actores, lógicas y reglas para la construcción de un sistema equitativo e integrado. Becas Ramón Carrillo-Arturo Oñativia, Ministerio de Salud de la Nación, Salud Investiga, 2009.

FOUCAULT, M. Genealogía del racismo. Buenos Aires: Altamira, 1992.

FREUD, S. Psicopatología de la vida cotidiana. Buenos Aires: Amorrortu Editorial, 1986. 
RICOEUR, P. La memoria, la historia, el olvido. Traducción de Agustín Neira. México: FCE, 2004.

ROSEN, G. History of Public Health. Baltimore: John Hopkins University, 1993.

ROVERE, M.; SACCHETTI, L. Surgimiento de la Enfermería Moderna. Buenos Aires: El Ágora, 2001.

SIERRA E IGLESIAS, J. Carlos Alberto Alvarado. Vida y Obra. Comisión Bicameral Examinadora de Autores Salteños, Salta, Argentina, 1993.
VERÓN, E. La semiosis social. Buenos Aires: Gedisa, 1987.

Recebido para publicação em abril/2012

Versão definitiva em agosto/2012

Suporte finaceiro: Universidad de Ottawa y el Fondo Teasdale-Corti del Gobierno de Canadá

Conflito de interesse: Inexistente 